scrotal wall, and if the testicle is attached well back in the scrotum its chances of staying down are that much the better. The correct fixation point is determined more easily from the outside using fine forceps rather than bimanually with a finger in the scrotum. The operator's index finger tends to flex upwards (anteriorly for the patient) with the inevitable result that the suture ends up a little more anteriorly placed than it need be.-I am, etc.,

Sheffield 10

Colin Maddox

\section{Tetracycline and Renal Function}

SIR,-In one of the recent Therapeutic Conferences on the treatment of pneumonia the use of tetracycline was discussed (2 October p. 42). The speakers mentioned some of the adverse effects of this drug, including liver damage and the rare Fanconilike syndrome resulting from outdated or improperly stored tetracycline. However, they failed to point out the comparatively common complication in the administration of this drug of increasing the blood urea nitrogen in patients with impaired renal function. Indeed, the patient under discussion in the article had a raised blood urea on admission. It is not uncommon to see patients referred whose chronic renal failure was well controlled until they were given tetracycline.

The observation of the azotaemic effect of tetracycline was first made by Bateman et al. in 1952.1 Since then a number of reports and studies have been published confirming this finding. ${ }^{2-4}$ Tetracycline has an antianabolic effect resulting in diminished utilization of amino-acids for protein synthesis and their degradation into urea. ${ }^{3}$ In addition, tetracycline has a natriuretic and diuretic action which may result in a hypovolaemic state which may contribute to the clinical and chemical changes of a rising blood urea. ${ }^{34}$ In those patients with renal disease the peak effect of raising the blood urea is often delayed and may not manifest itself for as long as a week after the drug is commenced.

With the onset of the cold weather and the associated epidemic of chest infections, especially in the elderly, it may be well to remember that many of these people have diminished renal function and the administration of tetracycline may increase the morbidity and in some instances the mortality as a result of raising the blood urea nitrogen.-I am, etc.,

Greenwich District Hospital,

C. B. BROWN

Bateman, J. C., Barberio, J. R., Grice, P., Klopp, Medicine, 1952, 90.763 .

2 Edwards, O. M., Huskisson, E C and Taylor, R. T., British Medical fournal, $1970,1,26$ 3 Shils, M. B., Annals of Internal Medicine, 1963, 58, 39

Katz, S., Archives of Internal Medicine, J1967, 120, 433.'

\section{Diabetic Clinics in General Practice}

SIR,-Like Dr. J. M. Malins and Dr. J. M. Stuart (16 October, p. 161) we have been interested in getting diabetic patients looked after by their own practitioner. However, we feel that the scheme which they describe has important omissions.

The cornerstone of any scheme should be a monthly diabetic clinic held in the practice by the practitioners. This should be conducted by one or two partners in the group who have a special interest in diabetes. We agree that a yearly visit for consultation with hospital staff is desirable and that at this meeting a year's records should be surveyed.

Such a scheme has been working in Wolverhampton for six months. Its main object is to achieve that the continuing care of more than $50 \%$ of diabetic patients from practitioners participating in this scheme should be carried out in practice rather than in hospital. Details of this will be published when the scheme has been in operation for a longer period.

Those running diabetic clinics in hospital have always been aware that many practitioners appear not to be interested in looking after diabetics, but this is often through lack of encouragement and opportunity. We have attempted to overcome this difficulty by holding monthly discussion groups with all practitioners involved, and the support for these has been most encouraging.-We are, etc.,

Wednesfield, Staffs

R. G. RuSSELI

Royal Hospital,

P. A. THORN

Wolverhampton

\section{Hospital Waiting Lists}

SIR,-The Department of Health states that the number of patients awaiting admission to regional hospital board hospitals on 31 December 1970 was $445,080.1$ The figure for teaching hospitals in England alone was ove 80,000 on that date, making a total of more than half a million. I wish to draw attention to a serious source of error in these statistics, from which so many conclusions are drawn. I refer to the tendency of numerous patients to "shop around," ending up on the waitinglists of more than one hospital for the treatment of the same condition, thus artificially and erroneously inflating the waiting list figure for the individual hospital as well as distorting the regional and national figures The wastage rate of offered beds in the hospital group I am principally concerned with amounts to not less than $10 \%$ a year. Occasionally it is possible to fill the bed with another patient, but all too often neither patient nor explanation reaches us, and the bed is wasted. Sometimes the patient's general practitioner will notify hospital A that the patient is now on hospital B's waiting-list, but there again one cannot expect a busy family doctor to carry out this additional chore as a routine.

The non-arrival of waiting list patients is a major administrative and clinical nuisance, and I should like to put forward two suggestions, one in the short term and one in the long, designed to bring the situation under better control.

In the short term, patients should be asked to pay a deposit to a hospital when placed on its waiting list for admission. This would be refunded in full when admitted or when the hospital is notified that the bed will not be required for any of the reasons given above. Should the patient ignore the admission notice and should no acceptable explanation of this reach the hos- pital within, say, a month of the dispatch of the notice, the hospital will retain the deposit, which should be large enough to make patients treat the hospital with proper consideration but not large enough to inflict hardship.

In the long term, one of the computers owned by the Department of Health should be programmed to record the name, address, N.I. number, hospital bed required, etc. of any patient newly put on a waiting list at any N.H.S. hospital. It would automatically cross-check this patient's details and would recognize double or treble bookings of hospital beds. It would direct the patient to the first bed becoming available, at which point it would cancel on his behalf other beds awaiting him elsewhere.

I venture to suggest that if these two suggestions were implemented-and they should not be administratively all that difficult-the patients would receive a better service, the N.H.S. would make better use of its resources, and clinicians and administrators would feel marginally less frustrated than they do at the present time.-I am, etc.,

Westcliff on Sea,
Essex

D. P. CHOYCE

1 North-east Metropolitan Regional Hospital Board Bed Use Statistics. Regional and Statistical Records Office, 1970.

\section{Psychosis and Ketamine}

SIR,-A housewife aged 29 years, was admitted to the Leicester Royal Infirmary for evacuation of the / uterus following an incomplete abortion. She was given $10 \mathrm{mg}$ of Cyclimorph (morphine tartrate and cyclizine tartrate) as premedication, and the operation was carried out under ketamine $300 \mathrm{mg}$ intravenously, given in one dose.

No more was heard of her until she was seen by a consultant psychiatrist a year later, having been referred by her family doctor as suffering from "hallucinations." She attributed these to the anaesthetic, since which she had never felt well. The psychiatrist elicited a history that she had "passing out spells," during which her "legs go like jelly." At times she became depersonalized and unreal, and she said that she felt she was leading her life "looking at a film."

The psychiatrist considered she was anxious but not depressed, and drew a comparison with patients who were suffering from the effects of LSD 25.

She was sent for psychometric tests. The psychologist elicited the fact that, following the anaesthetic, she experienced "visions of bright lights and thousands of faces;" these were not hostile and were not referred to her personally. She had a sensation of "being lifted very high into pink clouds." Since this episode she was somewhat depressed, with the idea of impending death and, at one time, thought she had a cerebral tumour.

Psvchometric testing showed: "Function at the upper end of the average range with an I.Q. of 110 (verbal); her performance score was considerably lower and reflected some loss of functional efficiency. Svmptom scales showed a moderate level of function within a neurotic setting, but the basic personality was not neurotic and the tests would indicate relative normality, her present con- 